\title{
Toxoplasma IgM positive in pregnancy: what does it mean from the perspective of the gynecologists?
}

\author{
Burcu Artunc Ulkumen ${ }^{1}$, Halil Gursoy Pala ${ }^{1}$
}

Sir,

Toxoplasma gondii infection in pregnancy occurs with maternal ingestion of cysts in undercooked meat or with maternal ingestion of oocysts found in water, food and soil (1). Contaminated under cleaned green salads (like garden rocket, parsley) and water may be important sources for women in Turkey. Although routine screening for toxoplasmosis in pregnancy is not recommended, this is not the case in daily practice and due to unnecessary screening and confounding test results, gynecologists should be also familiar with patients having the results of Toxoplasma $\operatorname{IgM}(+)$. One key-point for evaluation the toxoplasmosis-suspected pregnant woman is to know that congenital infection risk for the fetus is higher in third trimester; however, the risk of the injury for the fetus is greater in the first trimester (2). Pregnant women with $\operatorname{IgM}(+) / \operatorname{IgG}(-)$ should be screened in 1 to 3 weeks again. If seroconversion in Ig $G$ occurs, then infection is probably acquired during pregnancy and there is risk for congenital infection (3). Treatment is to be initiated with Spiramycin. Amniocentesis for amniotic fluid PCR should be performed after 16 weeks. A detailed fetal ultrasonography should be also performed. In case of $\operatorname{IgM}(+) / \operatorname{IgG}(+)$, the results should be confirmed. Toxoplasma Gondii avidity testing is reasonable at this stage (4). High-avidity $\operatorname{IgG}$ antibodies are detected at least 12-16 weeks after infection, so high-avidity IgG results show that the infection was started 16 weeks before. Low-avidity results may persist for a long period (even more than one year after acute infection), so only avidity tests should not be used $(1,5)$.

In our daily practice, we account the gestational week, the Ultrasonograhic findings with maternal serum results into account. In case of $\operatorname{IgM}(+) / \operatorname{IgG}(+)$; we also perform $\operatorname{IgG}$ avidity test. We initiate medical treatment and repeat the tests in 3 weeks. A significant increase in IgG titers (3-4 times) together with low-avidity IgG is suggestive for an acute infection. Fetal infection should be checked with amniocentesis
Acknowledgements: None.

Financial Support: This research received no specific grant from any funding agency, commercial or not-for-profit sectors

Conflict of Interest: The authors declared that they had no conflicts of interest.

\section{References}

1. Montoya JG, Remington JS. Management of Toxoplasma gondii infection during pregnancy. Clinical infectious diseases : an official publication of the Infectious Diseases Society of America. 2008;47(4):554-66.

2. Saadatnia G, Golkar M. A review on human toxoplasmosis. Scandinavian journal of infectious diseases. 2012;44(11):805-14.

3. Mumcuoglu I, Toyran A, Cetin F, Coskun FA, Baran I, Aksu N, et al. [Evaluation of the toxoplasmosis seroprevalence in pregnant women and creating a diagnostic algorithm]. Mikrobiyoloji bulteni. 2014;48(2):283-91.

4. Dogan K, Kafkasli A, Karaman U, Atambay M, Karaoglu L, Colak C. [The rates of seropositivity and seroconversion of toxoplasma infection in pregnant women]. Mikrobiyoloji bulteni. 2012;46(2):290-4.

5. Lappalainen M, Koskela P, Koskiniemi M, Ammala P, Hiilesmaa V, Teramo K, et al. Toxoplasmosis acquired during pregnancy: improved serodiagnosis based on avidity of IgG. The Journal of infectious diseases. 1993;167(3):691-7. 